\title{
Factors of determinism, uncertainty and stochasticity in stock and commodity markets
}

\author{
Nail Safiullin ${ }^{1}$, Bulat Safiullin ${ }^{1}$, Olga Schnaider, $^{2, *}$ \\ ${ }^{1}$ Kazan Federal University, Kremlyovskaya St, 18, Kazan, Respublika Tatarstan, 420008, Russia \\ ${ }^{2}$ Financial University under the Government of the Russian Federation, Leningradsky prospekt, 49, \\ Moscow, 125993, Russia
}

\begin{abstract}
One of the main methodological principles of modern economics is the separation of the positive and normative study area. Traditionally, the dominant regulatory approach is associated with a "pre-scientific" era - with the economic views of antiquity and the Middle Ages. Thus, the very evolution of the economic analysis can be considered as a process of gradual replacement of a regulatory elements and achieve ever greater degree of objectivity of research. In this paper, the economic theory of multidimensional stock and commodity market in the green economy is considered in detail. The current state of the theory of markets and market mechanisms is discussed. The research methodology and theory of multidimensional stock and commodity market in the green economy, adapted to the real conditions of the transformation of the Russian economy, are substantiates. Various forms of heterogeneity of market processes are identified and classified, including factors of demand, supply and competitiveness arising from the terms of the transformation of the economy attracting green investment.
\end{abstract}

\section{Introduction}

The economic theory of the multidimensional stock and goods market considered in this work belongs to positive sciences as it describes what is, not what should be which is characteristic areas of research of standard sciences. As shown in work, positive sciences essentially abstain from moral and ideological judgments concerning that, properly to treat the described phenomena, and limit themselves to studying of regularities of the studied objects. Though in practice it is never possible to draw an accurate distinction between positivistic and standard approaches, the difference between them is obvious [1].

The analysis, synthesis, induction and deduction belong to traditional methodological approaches of attracting green investment. In the theory of demand (or supply) as the analysis we will understand mental decomposition of volume of demand (supply) for parts with studying of each part determined by the corresponding factor of demand (supply). And under synthesis - connection of separate parts of demand (supply) in whole [2].

As for induction, it is one of the main methods of scientific knowledge demanding collecting and studying of specific factors and generalization of the received conclusions [3].

\footnotetext{
*Corresponding author: alyovina@gmail.com
} 
If induction is the movement "from the particular to the general", deduction - "from the general to the particular".

It is possible to refer the principles of a determinism to number of the basic methodological principles of the economic theory of the market, an indeterminism, the principle of "Okkam's razor" and others.

For each goods in each country there are structural forms of the competitive market [4]. Carrying out in-depth economic system studies in the sphere of the competitive markets needs new approaches.

The basis of this approach, in our view, are the fundamental principles of research systems. They include principles of a determinism and indeterminism formulated for the first time respectively by Pierre Laplace (1749-1827) and Leon Brilluen (1889-1969) for research of physical systems and processes. Relying on methodologies of the economic theory and general theory of systems and considering the competitive markets from system positions, we will formulate the basic principles of research and the competitive markets [5].

\section{Research methodology}

In research of market processes still prevails the deterministic principle consisting in that the knowledge of a condition of the competitive market as systems at present point of time allows to define its state precisely and unambiguously in any other time, the subsequent and previous [6]. The deterministic principle possesses a number of advantages that is availability and possibility of disclosure of the main economic processes proceeding in the market.

However no matter how skillfully and consistently this deterministic principle in the economic theory of various forms of the markets was used, it doesn't cover all difficulties of the market phenomena [7]. Many market processes for studying of which, apparently, the application of classical methods caused by principle of determinism is quite enough, at deep studying demand probabilistic approach. Relevance of development and introduction of probabilistic approach in research of the market remains still in many aspects, including questions of education of future economists and increase of efficiency of the solution of many practical tasks [8]. On definiteness of a state the competitive markets need to be subdivided on determined and stochastic, i.e. the markets have to be considered as the determined and stochastic systems.

\section{The determined market}

Consideration of the market in the form of the determined system follows from the principle of market determinism. The principle of market determinism consists that knowledge of condition of the market at present time allows defining precisely and unambiguously its state in any other time point, the subsequent or previous.

The condition of this market is defined by set of sellers, buyers, a look and number of goods and their competitiveness. In particular, the market - a polypoly will be considered as the closed (isolated) system in which action on the market of environment is represented by some set of entrance volumes on any intervals of time along with the fixed model which operates transition of the market as systems from one state to another under the influence of entrance volumes [9-12].

Transition from a general market model to the determined model is caused by possibility of such supervision over a condition of the closed competitive market as a result of which all volumes defining this state are precisely fixed. An example of such market is the polypoly characterized by emergence of the perfect competition in this market. 


\section{Polipol as a determined competitive market}

Condition of the market (as economic system) when influence of each participant of economic process on the general situation is so that it can be neglected [13].

It testifies to lack of any fluctuations in condition of the market. Besides, in conditions of modern competition each subject of market economy at decision-making proceeds from the market prices which are as much as precisely set to it and can't influence pricing. In this regard, the market prices are also not fluctuant, i.e. are of a deterministic nature. The perfect competition assumes full mobilization of production resources. Each owner of such resource unambiguously chooses a sphere of application, favorable to himself and isn't limited in this choice by anything, except the competition from similar resources.

The concept of the perfect competition includes also full knowledge of all without exception participants of production of market economy about those economic opportunities which are available in it.

The following signs of the perfect competition are usually allocated: plurality of sellers and buyers, uniformity of the let-out goods, lack of possibility of buyers and sellers to influence the price, mobility of production resources, absolute knowledge of businessmen of a condition of the market [14].

Abstraction of the stock market in the form of the determined system allows studying demand, the supply and the competition in this market to the smallest details, being based on known methodologies of the determined systems and methods of the economic theory and theory of the competition.

We introduce the following definition of determined market. The market is called determined if it is a priori known that result of supervision of demand, supply and competitiveness of the competing objects (goods and services) in this competitive market at repeated carrying out experiment in invariable conditions is the same (unambiguous).

Thus, determined and therefore the simplest market structure is the structure of the perfect competition where the market behavior of sellers and buyers consists in the adaptation to an equilibrium condition of market "environment". The perfect competition is the determined market structure, at which:

- sellers agree to the prices as a reality and can't influence consciously them, i.e. can't affect structure of the market;

- access of new sellers to branch is limited by nothing and their number is controllable;

- sellers don't develop joint strategy on the change in price for goods, i.e. changes of structure of the market;

- buyers aren't capable to influence the prices;

- market information is available to all participants of trade.

We will note that market structure in which the first four signs join, is also named the market of the pure competition. Violation or non-performance of one of signs of the determined market leads to uncertainty and the market structure becomes stochastic.

\section{Uncertainty and stochastic markets}

The principle of a market indeterminism consists in denial of possibility to precisely define a condition of the market as the closed system at present of time, therefore, to completely predetermine its future development.

The principle of a market indeterminism is alternative to the principle of market determinism. It is explained by the complexity, heterogeneity, ambiguity, and unpredictability of processes and phenomena that occur in a competitive market.

The principle of market indeterminism doesn't deny possibility of the determined market, it only attributes to each act of research and knowledge of the competitive market the 
uncertainty area connected with limited possibilities of definition of condition of market and its environment.

Qualitative and quantitative definiteness is inherent in market processes and phenomena. Therefore the economic theory widely uses mathematical, statistical techniques and research tools which allow revealing the quantitative party of market processes and phenomena, their transition to a new quality. At the heart of definition of concept of stochastic market the special role is played by probabilistic approach.

The principle of market indeterminism allows characterizing more real situation in the market, i.e. unpredictable stochastic nature of processes (processes of supply and demand) and the competition phenomena. At the same time this principle also has negative character consisting in complexity of the phenomenon as any supervision over condition of the market is treated as an event with definitely unpredictable result. Unlike the principle of market determinism which specifies a way of construction and use of a mathematical market model (for example, in the form of a ratio of criteria of competitiveness), the principle of market indeterminizm indicates only a situation of uncertainty which arises after supervision - after carrying out the economic analysis regarding determination of competitiveness.

For transition to the following stage of knowledge of the competitive market quantitative formalizations of abstract representations it is necessary to enter a quantitative measure of uncertainty - probability of an event.

We will assume that the sales volume of goods or measurement of competitiveness of goods in this market may be repeated many times at the set not changing complex of conditions. For example, at that type of market, number of sellers, number of buyers, ruble exchange rate and political conditions remain unchanged.

We introduce the following notion of stochastic market.

We will call the market stochastic if a priori (before observation) we know only the set of possible (imaginable, predicted) results of supervision of competitiveness of the competing objects which can be fixed at multiple repetition of experiment in invariable conditions [15].

In the latter case result of competitiveness of the objects competing among themselves in this market is impossible to accurately predict in advance.

However if to make a set of observations in invariable conditions, the following regularity will be found: results of competitiveness can differ from each other, but the average values relating to a set of results show stability - remain approximately constant. The observed stability of average results of competitiveness of the competing objects - statistical regularity - is a reflection of probabilistic regularity which characterizes considered experiment in this stochastic market under the set conditions.

Thus, the uncertainty situation in the market is characterized by the set set of casual events, i.e. competitive factors, and for each event "A" existence of a quantitative measure is postulated - probability P (A) events "A" - equivalent frequency of emergence of an event in this series of observations at which statistical stability of frequency is shown.

So, the new class of economic-mathematical models - probabilistic models which adequacy is confirmed by practice more and more gets into economic science. For example, the majority of new methods is based on econometric models, concepts and techniques. Development of econometrics is based and is closely connected with studying of various sections of the economic theory, including microeconomics [16].

The evidence of the world recognition of probabilistic approach is award of a number of Nobel Prizes on economy: an award of 1989 - T. Haavelmo for the explanation of probabilistic fundamentals of econometrics and the analysis of simultaneous economic structures; an award of 2000 - to J. Hekman for development of the theory and methods of the analysis of selective selections and Daniel L. McFadden for development of the theory and methods of the analysis of models of a discrete choice. 


\section{Stochastic markets}

Examples of stochastic markets are the following markets characterized by competition forms: oligopoly, monopoly and monopolistic competition (imperfect competition).

Monopoly as stochastic market. It is known that such type of the market on which only one firm is the seller of goods which has no close substitutes is called monopoly. Therefore the monopolist can affect the price of the sold goods in a random way, purposely reducing output. Uncertainty of the price of goods for consumers is dictated by conditions of market demand. The monopolist has more freedom of action, than the consumer. For example, the monopolist can resort to practice of price discrimination when he sells goods for which further resale is difficult or impossible at all. Secondly, the monopolist has ability to differentiate the consumers wishing to acquire goods, in accordance with their capabilities and willingness to pay. When performing these conditions the monopolist divides the market into a segment and sells such quantity of production which maximizes its profit in each of them.

The television cable company of the small city or city area can be the monopolist, for example, after all her TV viewers have no ability to address to access another provider.

Market of oligopolistic competition. Some firms dividing the market form market structure like an oligopoly. The oligopoly with various force of the competition can yield result, comparable with a situation of "pure monopoly". Firms function in the conditions of coherence, making the decision, each participant has to consider possible reaction of competitors. The oligopoly accepts all intermediate options from the perfect competition to "pure" monopoly. For example, if air transportation between two large cities is carried out by two-three companies, they try to avoid the competition to keep ticket prices at the high level.

The market of monopolistic competition combines features of monopoly and the market of perfect competition.

The essence of stochasticity of the market of monopolistic competition is that each firm sells production on which there are a lot of close, but imperfect substitutes which are incidentally fluctuating at price and quality. Differentiation can be connected with production (for example, various sorts of beer) or location of shop. Various sorts and location of shops initiate uneven demand that allows sellers selling goods at various price.

Thus, stochasticity of the monopolistic market is defined by the established methods of monopolistic practice:

- random imposing discriminatory conditions of contracts on partners ;

- in a random way increase, decrease or maintenance of the prices;

- creating a deficit in random times by withdrawal of goods from circulation, restriction or cessation of production of goods;

- imposing on buyer in any time of the compulsory range of unpredictable quality, unexpected terms of sale of these or those goods;

- random abandoning the business with potential partners, etc.

Applications of statistical receptions methods of unfair competition take a special place in the market. Techniques and actions of competitors have unpredictable character. Unpredictability of methods of competitors is shown in their following actions:

- symbolical use of someone else's trademark, trade name, marking of goods, unauthorized copying of a form, packing, external design of goods of other firms;

- incorrect comparison of goods in the course of advertizing activity;

- influencing the decision of the competitor to acquire advantage over him;

- misleading consumers regarding the characteristics, consumer characteristics, method and place of manufacture of the goods;

- direct deception of consumers and customers; 
- acquisition of a trade secret of the competitor without his consent, unauthorized use and disclosure of confidential information.

On the basis of studying of actions and methods the state antitrust law has to be directed against practice of unfair competition.

At a market research factors of supply and demand can be considered as determined, and stochastic. At competitiveness research special value is allocated for the price and quality of goods and services.

The principle "with other things being equal" which assumes an invariance of all factors and circumstances that is a studying subject. For example, it is considered that at an advance in price demand for goods falls, - but the movement of the prices of interchangeable goods consciously isn't taken into account.

This principle yields satisfactory results in the conditions of stationarity and uniformity of factors in market situations, i.e. for the developed market economy. In the conditions of heterogeneity of factors of supply and demand this principle can lead to unexpected results if the price of interchangeable goods grows too quickly, demand for goods which we consider, can increase.

Important methodological assumption is the principle of "Okkam's razor" for the first time formulated by the English philosopher-scholastic William Okkam at the beginning of the XIV century. He claimed that the concepts which don't have the basis in skilled knowledge or intuition have to be removed from science (being cut, as if by razor).

In modern understanding this principle is usually treated as a priority of those concepts and conclusions which demand less assumptions, than others. For example, if a certain hypothesis A is fair at one assumption, and the hypothesis B - at several, truth probably is the hypothesis A.

Here we note that the theory of demand developed by us in space of many factors leads to considerable reduction of number of assumptions in comparison with the theory of demand of A. Marshall. That's why from these positions the theory of demand offered in this work will be more preferable, than the classical theory of A. Marshall as well.

\section{References}

1. P. Aghion, J. Tirole, Journal of Political Economy 105(1), 1-29 (1997)

2. E.W. Anderson, C. Fornell, D.R. Lehmann, M.W. Sullivan, Marketing Science 12(2), 125-143 (1993)

3. N.G. Bagautdunova, L.N. Safiullin, N.Z. Safiullin, A.Z. Novenkova, Proceedings "2nd Annual International Conference on Micro and Macro Economics, 77-81 (2012) doi: 10.5176/2251-2055_MME1224

4. R.N. Bolton, K.N. Lemon, Journal of Marketing Research 36(2), 171-186 (1999)

5. E.R. Cadotte, R.B. Woodruff, R.L. Jenkins, Journal of Marketing Research 24, 305-314 (1987)

6. W.E. Deming, Quality, Productivity, and Competitive Position (Cambridge, MIT Press, MA, 1982)

7. M. Gambu, Klaster analisys (Finace, Moscow, 1988)

8. K. Isikava, Japanese method of quality (Economy, Moscow, 1998)

9. L.N. Safiullin, G.N. Ismagilova, N.Z. Safiullin, M.R. Safiullin, Proceedings 2nd Annual International Conference on Micro and Macro Economics, 61-63 (2012) doi: 10.5176/2251-2055_MME1223

10. J.M. Juran, Quality by Design: The New Steps for Planning Quality into Goods and Services (The Free Press, New York, 1992) 
11. J.-J. Laffont, The Economics of Uncertainty and Information (The MIT Press, Cambridge, MA, 1989)

12. J.-J. Laffont, D. Martimort, The Theory of Incentives: The Principal-Agent Model (Princeton University Press, Princeton, NJ, 2002)

13. I. Macho-Stadler, J.D. Pérez-Castrillo, An Introduction to the Economics of Information: Incentives and Contracts (Oxford University Press, Oxford, 2001)

14. N.A. Morgan, D.W. Vorhies, Journal of Product Innovation Management 18(6), 396-407 (2001) doi: 10.1016/S0737-6782(01)00112-6

15. P. Nelson, Journal of Political Economy 78(2), 311-329 (1970)

16. R.L. Oliver, Satisfaction: A Behavioral Perspective on the Consumer (M.E. Sharpe, New York, 2009) 